\title{
Contemporary perspective of energy efficiency: essentials, content, challenges, implementation in the Russian Federation
}

\author{
E Yu Gorbachevskaya ${ }^{1}$ \\ ${ }^{1}$ Irkutsk National Research Technical University, 83 Lermontov str., Irkutsk, 664074, \\ Russia
}

\begin{abstract}
Natural resources conservation and sustainable living have become important issues worldwide. Among natural resources, energy is one of the important prerequisites for sustainable development. Therefore, in order to meet the high demand for energy, it is necessary to bring its sustainable consumption to the forefront of the development strategy of construction industry. The construction sector development in the Russian Federation is largely determined by national projects whose main goal is to provide citizens with comfortable and affordable housing. The national program announced by the government can be successfully implemented by the means of energy-efficient technologies usage, in particular, while building low-rise housing.
\end{abstract}

Currently, the Russian economy is moving towards the energy-saving path of development. This trend originated in 1990 when there appeared a doctrine involving the rationing of buildings; the main purpose of this doctrine was to minimize energy consumption. The government developed regulatory documents that made the construction complex of the Russian Federation apply energy-efficient technologies in the construction and management of buildings at the state level. As a result, the concept of "an energy-efficient building" was introduced in the construction industry and in the country's economy.

The conceptual framework of the energy-efficient sphere is described in the Russian Building Norms and Rules (SNiP) 23-02-03 Thermal Protection of Buildings. However, it should be noted that the norms of this SNiP explain energy efficiency only as a property of an object and its engineering systems that provides the necessary level of heat energy consumption in order to maintain optimum microclimate parameters of housing [1].

In the process of energy-efficient technologies development the term "energy efficiency" has changed a lot and the boundaries of its influence in the construction sector have expanded. Due to the fact that energy efficiency technologies include not only the use of thermal energy, but also the use of other types of energy resources and energy, it is necessary to give a more precise definition of this concept.

In the process of realizing the entire technological potential of energy-efficient technologies, three categories of measures can be applied; they are shown in Figure 1 (figure 1).

Categories of measures

low-cost measures

include cleaning up when using fuel and energy: eliminating energy losses during transportation and storage, implementing energyefficient technological regimes, replacing excess power equipment sunnlving consumers with energv meters. etc. 
Figure 1. Categories of measures used for realizing the technological potential of energy-efficient technologies

The energy-efficient technologies development in a country is determined by numerous measures and factors. Energy efficiency factors include the structure of the country's economy, the type of the industrial base used, the exchange rate of the national currency, the area and climate of the country, as well as affordability of energy services [2]. In the Russian Federation electricity consumption is increasing every year, which undoubtedly causes both the environmental degradation and increased citizens' expenses associated with paying electricity bills (figure 2) [3].

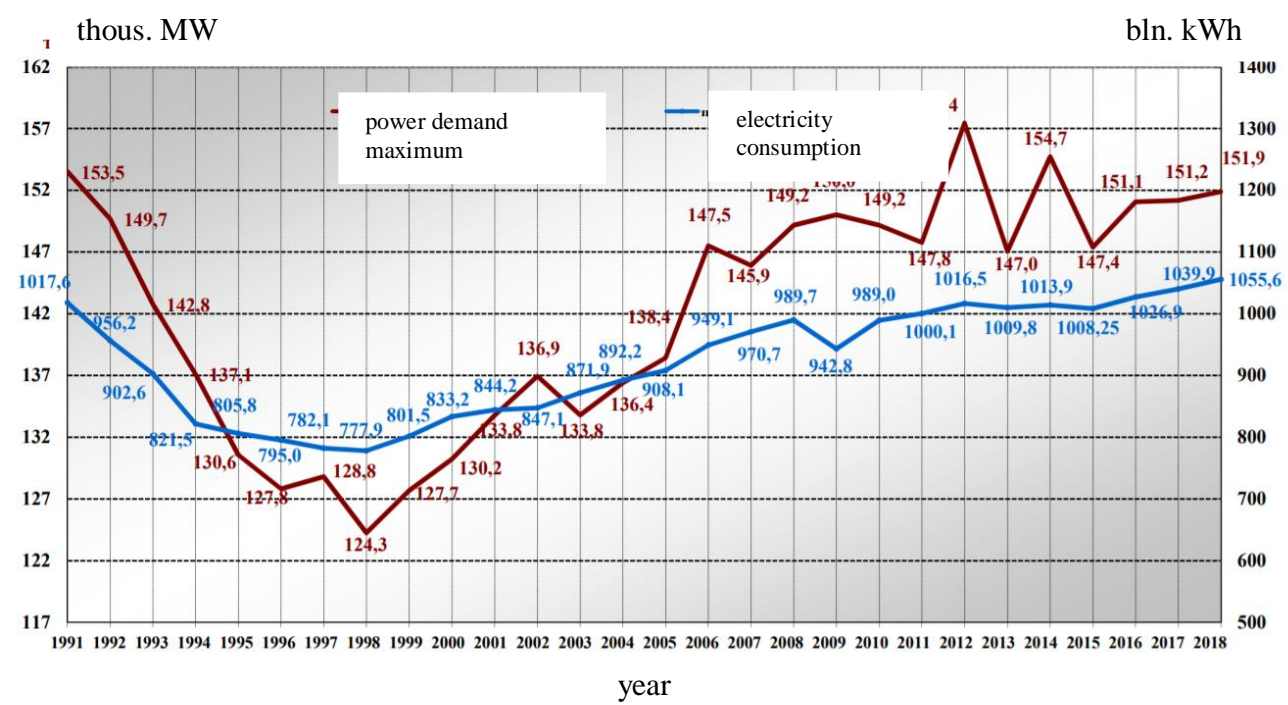

Figure 2. Dynamics of demand for electricity from 1991 to 2018

Thus, in 2019, there was another increase in electricity tariffs by an average rate of $4 \%$. Since the territory of the Russian Federation is rather large in comparison with other countries, in Russia the electricity tariff rate varies depending on the region. In 2019 the lowest tariff was recorded in the 
Irkutsk region -1.06 , the highest tariff in large cities was recorded in Moscow - 5.38. If one considers all the regions of the Russian Federation, then the highest tariff is in the Chukotka region - 8.2 [3]. These data indicate a fairly high cost of electricity for the Russian citizens. According to the officials, high tariffs should stimulate citizens to use energy-saving technologies. However, the problem of increased cost of energy resources is one of the main state problems. If the problem of higher cost of energy resources is solved, it will both strengthen the position of the Russian Federation in the list of developed countries of the world and provide an increase in the standard of citizens' living. Russia is a resource base for the majority of countries in the world; however, the huge base of fuel and energy resources in our country does not involve energy waste, since only in an open market economy the energy efficient management can be the most important factor in Russian goods and services competitiveness $[4,5]$. Currently, the state has a strategic goal in the economic sphere - to double the level of gross domestic product by 2025 . This goal can be achieved only by changing the understanding of energy conservation, and, as a result, by introducing energy efficiency technologies.

The Russian Federation as well as all the countries around the world recognize the urgent need to change existing approaches to energy usage. Ensuring energy security, reducing energy prices are of primary importance in the development of energy efficiency policies.

The focus on the development of energy-efficient technologies in the Russian Federation can be traced in The Energy Strategy of Russia for the Period up to 2030, which treats energy conservation and energy efficiency as the main issues. Besides, various state programs involve grants of at least 50 billion rubles $[6,7]$ to the budgets of constituent entities of the Russian Federation allowing them to implement regional programs. Nevertheless, the state budget is not enough to popularize energyefficient technologies; therefore, the issue of raising extrabudgetary funds for energy-efficient projects implementation is still relevant. The Government of the Russian Federation is developing and approving regulatory acts, decrees and laws that contribute to reduced energy consumption while constructing new buildings, reconstructing and overhauling. For example, in order to stimulate businesses to switch to the energy-efficient policy, the state developed the economic levers including tax incentives and potential reimbursement of interest on loans whose funds were used for energy saving projects or projects aimed at improved energy efficiency of buildings.

Based on the experience of foreign countries, the Support Fund for the Reform of Housing and Utilities Sector of the Russian Federation together with 42 constituent entities of the Russian Federation implements pilot projects of energy-efficient blocks of flats as part of programs that allow relocating citizens from emergency housing. At the end of 2018, 40 residential buildings were commissioned, the remaining 17 houses are at the design and construction stages [8]. These pilot projects contribute to the development of sustainable construction in Russia, which aims at reducing the impact of housing development on the environment and human health.

One of the major projects implemented in Russia is Green Balance private houses located in the Moscow region. Initially, their peculiarity lies in the fact that they demonstrate the usage of energyefficient construction technologies in various designs: traditional and original $[9,10]$.

When designing a Green Balance residential building, the architects' aim was to reduce the total costs during construction and subsequently during the operation of the house, as well as to build a house with low-energy heating. The project was implemented by the aid of investments and application of technologies of Rockwool company, which is a major supplier of energy-efficient technologies not only in Russia but worldwide.

A Green Balance residential building has an area of $208 \mathrm{~m} 2$; the living space is $132 \mathrm{~m} 2$. The project implementation period was 15 months (figure 3 ). 

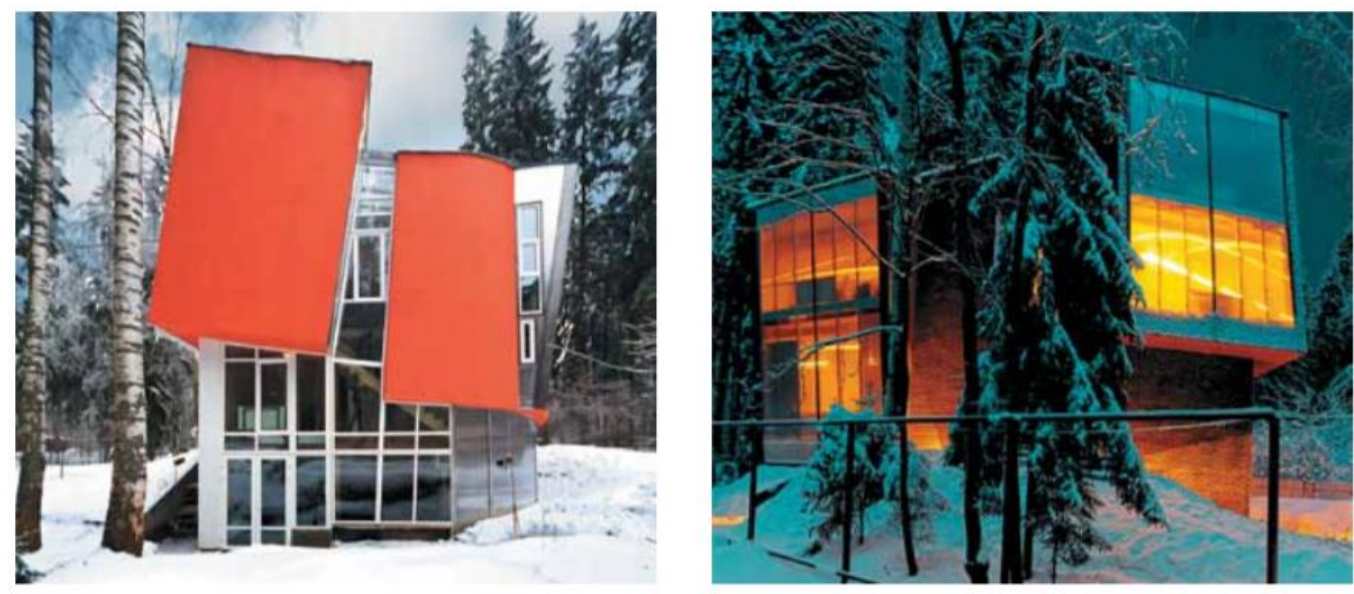

Figure 3. House architecture

The architectural solutions promote energy efficiency of the house - due to the compact shape of the recessed semi-basement floor (which is also used as a residential floor), the area of building envelopes to the usable area of the house is less than in traditional houses. This fact made it possible to ensure energy efficiency of the house and reduce the number of building envelopes that allow heat to pass through [11]. Besides, due to these architectural solutions natural resources can be used for the operation of the building all year round, as there are no energy costs for cooling in summer and in winter the house is heated by solar energy. The window openings provide the maximum flow of daylight into the house throughout the year, which allows saving on artificial lighting.

Moreover, a number of measures have been taken to increase the level of livability in the house. One of such measures is creation of sound comfort as building envelopes are made of stone wool which absorbs noise from outside.

As for the utilities technologies in the Green Balance house they are as follows: heating and hot water supply of the house are based on the individual boiler station; the boiler is convertible, namely, it is a solid fuel boiler allowing installing a high efficiency gas or diesel burner. Brick fuel is used [12].

Traditional radiators are used for water heating system. The ground floor space is additionally warmed by heated water floor. For heating thermal radiation is partly used, it is obtained due to the built-in heating of the wall surface.

The usage of energy-efficient technologies allowed the Green Balance house to reach energy consumption of $63 \mathrm{kWh}$ per $\mathrm{m}^{2}$ per year, which is $60 \%$ less than the standard indicator. Thus, the house can get $A$ energy efficiency class (see figure 4) [13]. 
Rubles per $\mathrm{m}^{2}$ of the floor

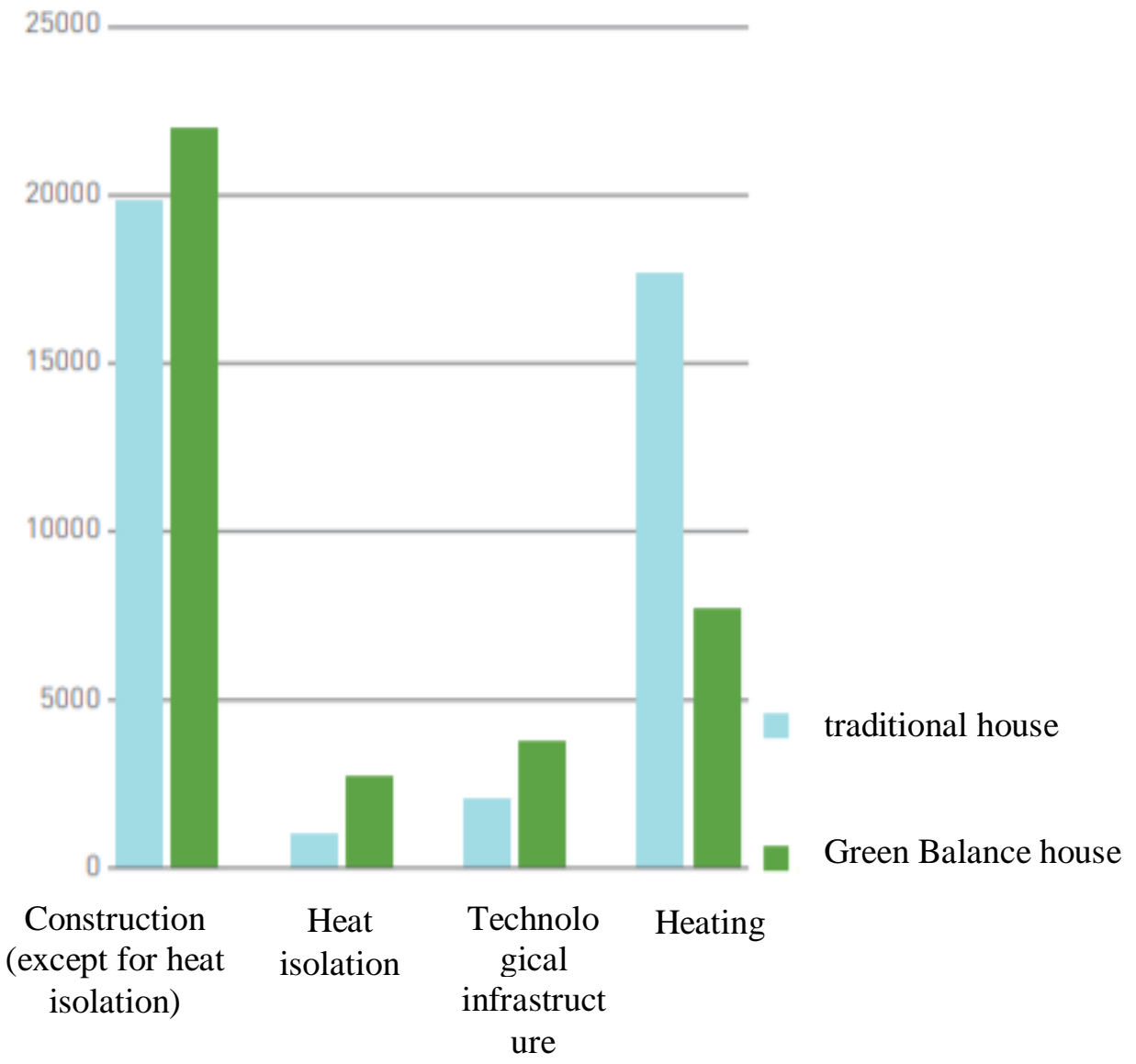

Figure 3. Indices of the house energy consumption

Considering investment attractiveness, we can draw the following conclusion: at the design and construction stages investments in energy-efficient technologies increased the cost of construction by $14.5 \%$, however, due to reduced energy costs for heating residents can save up to 32850 rubles annually [14].

Thus, the project of Green Balance houses has the following characteristics:

- Energy efficiency class of $A$;

- Comfortable microclimate;

- Stylish and non-standard design;

- Good soundproofing;

- Reduced energy consumption by $60 \%$ compared with current standards;

- Annual savings - 32850 rubles.

In this regard, it can be argued that the Green Balance house indicates that there are no barriers to the development of energy-efficient construction in Russia, as it confirms its simplicity, efficiency and environmental friendliness.

The implemented projects allow stating that initially energy efficient technologies should be used in the type of construction that has promising developments. Low-rise housing construction can be referred to such type of construction. In 2018, 75.3 million of $\mathrm{m}^{2}$ were built in the Russian Federation, and the share of low-rise housing construction reached the highest level for the entire period of statistical survey $-42 \%$ of the total volume of housing commissioned in 2018. Thus, low-rise housing 
construction can be defined as one of the most comfortable, resource-saving and cost-effective types of housing allowing people to live in harmony with nature.

The relevance and diversity of the issue of improving the energy-efficient technologies performance in low-rise building construction determine the need to improve the methodological foundations of management and to introduce energy-efficient technologies in production and economic processes. Improving and implementing relevant methodological foundations and principles will allow developing a systematic approach to the issue of energy-efficient technologies mass use in the Russian Federation.

\section{References}

[1] Sibikin Yu D 2017 Power Supply of Industrial and Civil Buildings p 89

[2] Kudrin B I 2016 Power Supply p 160

[3] Statistical Review of World Energy [Electronic Resource] URL: https://web.archive. org/web/20150813113139/http://www.bp.com/en/global/ corporate/about-bp/energyeconomics/energy-outlook.html (access date: 15.02.2020)

[4] Makarov A A and Voropay N I 2018 Systemic Research in the Energy Sector: Methodology and Results p 309

[5] Plakitkina L S and Plakitkin Yu A 2017 Coal Industry of the World and Russia. Analysis, Trends and Development Prospects p 374

[6] Statistical Yearbook of World Energy [Electronic resource] URL: https://yeabook.ennerdata.ru/ (access date: 02.16.2020)

[7] Aran Shankar V K, Umashankar S, Paramasivam S and Hanigovszki N A 2016 Comprehensive Review on Energy Efficiency Enhancement Initiatives in Centrifugal Pumping System Applied Energy $\mathbf{1 8 1}$ pp 495-513

[8] Lontsikh P A, Moskvitina V A, Golovina E Yu and Kibirev Yu V 2019 Relevant Trends in Construction Industry of the Irkutsk Region University News. Investments. Construction. Real Estate 9 pp 10-25

[9] Kazakbaev V, Prakht V, Dmitrievskii V, Ibrahim M, Oshurbekov S and Sarapulov S 2019 Efficiency Analysis of Low Electric Power Drives Employing Induction and Synchronous Reluctance Motors in Pump Applications Energies 12 doi: 10.3390/en12061144

[10] Topchiy D V, Yurgaitis A Yu, Kravchuk A S and Shevchuk D A 2019 Energy Audit of Capital Construction, Reconstruction and Reprofiling Facilities before Commissioning University News. Investments. Construction. Real Estate 9 pp 134-143

[11] Yanovsky A B 2019 Results of structural reorganization and technological re-equipment of the coal industry of the Russian federation and objectives for prospective development Russian Coal Journal 8 pp 8-16

[12] Volokitina V M and Gedich T G 2017 Investment Component in the Current Situation and Development of the Coal Industry in Russia Economic Analysis: Theory and Practice $\mathbf{1 6} \mathrm{p}$ 1262

[13] Chupin V R and Dushin A S 2019Assessment of the Reliability of Providing Consumers with Water. Development of Reliability Indicators of Water Supply to Consumers. University News. Investments. Construction. Real Estate 9 pp 578-593 DOI: 10.21285 / 2227-29172019-3-578-593

[14] Topchiy D V, Klimina V V, Kodzoev and Khaliullin I M 2019 Research of the Stress-Strain State of the Structure by Tensometric Method in the Renovation Implementation University News. Investments. Construction. Real Estate 9 pp 372-383 DOI: 10.21285 / 2227-29172019-2-372-383 